06

\title{
Оптическая характеризация дефектности двумерных кристаллитов $\mathrm{MoS}_{2}$
}

\author{
(ㄱ С.Д. Лавров, А.П. Шестакова, А.Ю. Авдижиян, Е.Д. Мишина
}

Московский технологический университет (МИРЭА), Москва, Россия

E-mail: sdlavrov@mail.ru

\section{Поступило в Редакцию 3 июля 2017 г.}

Представлены результаты исследований двумерных кристаллитов дисульфида молибдена, полученных методом механической эксфолиации и химического осаждения из газовой фазы. Показано, что оба метода позволяют получить отдельные кристаллиты моноатомной толщины со схожими оптическими свойствами. Обнаружено, что кристаллиты, созданные при помощи метода осаждения из газовой фазы, обладают большей концентрацией дефектов по сравнению с кристаллитами, полученными методом механической эксфолиации.

DOI: 10.21883/PJTF.2018.22.46917.16949

Дихалькогениды переходных металлов (ДПМ) в настоящее время являются одними из наиболее перспективных двумерных материалов для создания принципиально новых устройств гибкой нано- и оптоэлектроники. К достоинствам монослоев ДПМ можно отнести прямую запрещенную зону и достаточно высокую подвижность носителей зарядов, а также высокое отношение уровней тока логических элементов на их основе во включенном и выключенном состояниях. На их основе уже созданы экспериментальные образцы ряда устройств: фототранзисторы, датчики газа, солнечные элементы, запоминающие устройства, светоизлучающие источники электролюминесценции, источники эмиссии электронов и др. [1,2].

В настоящее время разработка методик синтеза двумерных слоев ДПМ представляет собой ключевую технологическую задачу. Наиболее отработанными среди них являются методы механической эксфолиации и химического осаждения из газовой фазы (ХОГФ) [3,4]. Однако характеристики материалов, полученных методами механической эксфолиации и ХОГФ, существенно различаются. В настоящей работе проводится исследование влияния перечисленных методов на оптические 


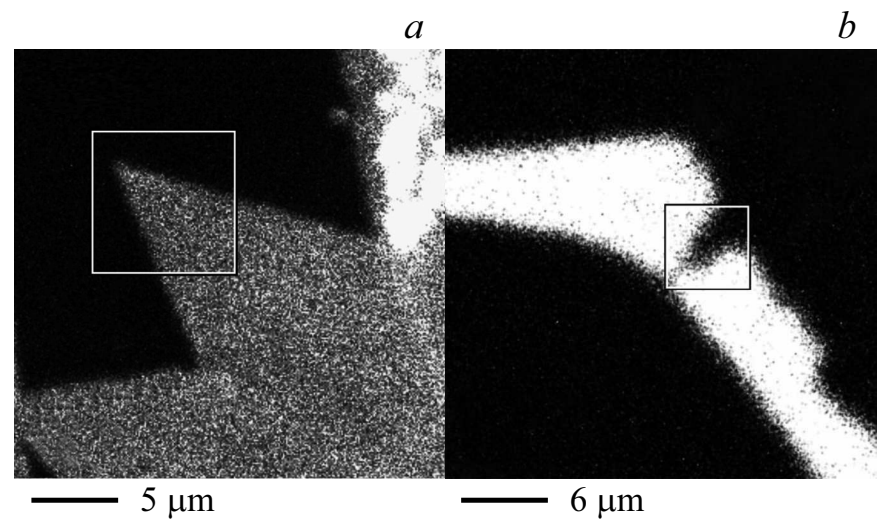

Pис. 1. Изображения кристаллитов $\mathrm{MoS}_{2}$, полученные при помощи люминесцентной конфокальной микроскопии. $a$ - кристаллиты, созданные при использовании методики ХОГФ, $b$ - кристаллиты, созданные при использовании методики механической эксфолиации. Изображения получены на фиксированной длине волны, равной $665 \mathrm{~nm}$.

свойства получаемых с их помощью двумерных полупроводниковых материалов.

В качестве исследуемых материалов были выбраны наиболее широко применяемые в устройствах наноэлектроники монослойные кристаллиты $\mathrm{MoS}_{2}$. Двумерные структуры $\mathrm{MoS}_{2}$ были получены как методом механической эксфолиации, так и методом ХОГФ.

Выращивание объемных образцов ДПМ первой серии для последующей эксфолиации осуществлялось из исходных компонентов (Мо и S) при заданных температурах согласно [5]. Синтезированные объемные образцы наносились на подложки $\mathrm{SiO}_{2} / \mathrm{Si}$ с толщиной окисла $\mathrm{SiO}_{2}$, равной $90 \mathrm{~nm}$, при помощи стандартного метода механической эксфолиации [6]. Вторая серия образцов была получена с использованием стандартного метода ХОГФ [7].

Свойства полученных образцов были проанализированы при помощи стандартных экспериментальных методик, применяемых для двумерных графеноподобных структур. Для этого был использован многофункциональный экспериментальный стенд на базе сканирую-

Письма в ЖТФ, 2018, том 44, вып. 22 


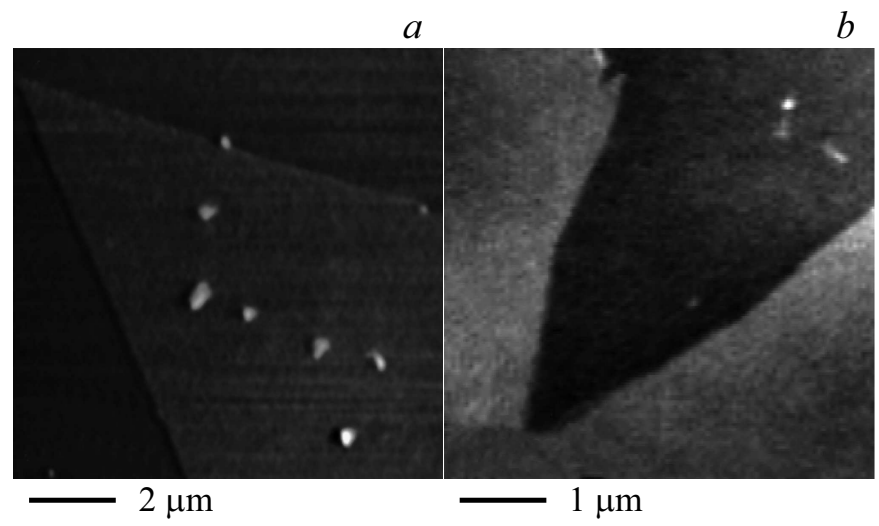

Рис. 2. Изображения кристаллитов $\mathrm{MoS}_{2}$, полученные при помощи ACM. $a-$ кристаллиты, созданные при использовании методики ХОГФ, $b-$ кристаллиты, созданные при использовании методики механической эксфолиации.

щего конфокального оптического микроскопа Alpha300s+ (WITec, Германия), монохроматора Shamrock 500i (Andor, Великобритания) и титан-сапфирового фемтосекундного лазера TiF-50 (Авеста-проект, Россия) [8]. Для исследования люминесцентных свойств дополнительно использовалось непрерывное лазерное излучение с длиной волны $532 \mathrm{~nm}$.

Исследования распределения интенсивности люминесценции по поверхности изучаемых материалов осуществлялись в режиме люминесцентной микроскопии. Данная оптическая методика также позволяет предварительно оценить толщину исследуемых двумерных полупроводниковых структур, что отражено в ряде работ $[9,10]$. Результаты, полученные при помощи этой методики, представлены на рис. 1, $a$ и $b$. При получении изображений кристаллитов длина волны на детекторе фиксировалась на центральной спектральной линии люминесценции $\mathrm{MoS}_{2}(665 \mathrm{~nm})$. Как видно из представленного на рис. 1, $a$ изображения кристаллита $\mathrm{MoS}_{2}$, полученного методом ХОГФ, распределение интенсивности экситонной люминесценции не является однородным. Данный факт может свидетельствовать о наличии структурных дефектов, возникновение которых обусловлено появлением градиента концентрации электронов на поверхности при выращивании. Это является причиной

Письма в ЖТФ, 2018, том 44, вып. 22 


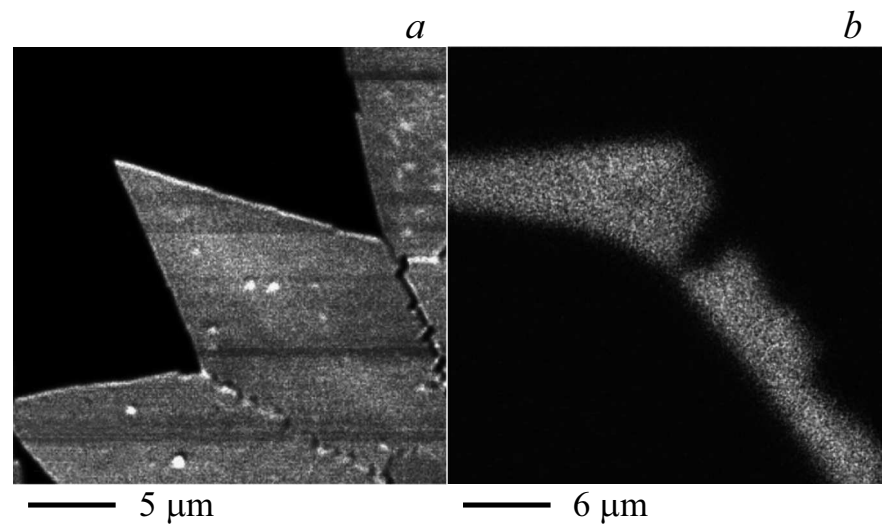

Рис. 3. Изображения кристаллитов $\mathrm{MoS}_{2}$, полученные при помощи нелинейнооптической конфокальной микроскопии. $a-$ кристаллиты, созданные при использовании методики ХОГФ, $b$ - кристаллиты, созданные при использовании методики механической эксфолиации.

возникновения вакансий, что в свою очередь приводит к изменению локальной плотности носителей заряда $[11,12]$. Такие эффекты могут свидетельствовать о наличии краевых эффектов в данных структуpax [10]. Кристаллит, полученный методом механической эксфолиации, таких особенностей лишен (рис. $1, b)$.

Для точного определения толщин отдельных кристаллитов ДПМ была использована методика атомно-силовой микроскопии (АСМ). Изученные данным методом области поверхности выделены на рис. 1, $a$ и $b$ квадратами. Топография отдельных кристаллитов $\mathrm{MoS}_{2}$, полученных методами ХОГФ и механической эксфолиации, расположенных в этих областях, показана на рис. 2, $a$ и $b$ соответственно. Толщина обоих исследуемых кристаллитов составляет приблизительно $1 \mathrm{~nm}$, что, согласно литературным данным, соответствует монослойному кристаллиту [13]. На рис. 2, a на поверхности кристаллита видны отдельные дефекты, имеющие размер порядка $200 \mathrm{~nm}$ в диаметре. Кристаллит, созданный при использовании метода механической эксфолиации (рис. $2, b)$, является более однородным и не обладает структурными дефектами. 
Результаты, полученные при помощи нелинейно-оптической микроскопии, представлены на рис. $3, a$ и $b$. Распределение интенсивности второй оптической гармоники в случае кристаллитов, созданных при использовании метода механической эксфолиации, является однородным. При этом на изображении кристаллитов, полученных при помощи метода ХОГФ, видны контрастные линии, отвечающие за границы зерен при росте монослойных пленок [14], и структурные дефекты, которые были визуализированы с помощью АСМ.

Таким образом, было показано, что для изготовления однородных и бездефектных двумерных кристаллитов $\mathrm{MoS}_{2}$ наиболее оптимальным является использование метода механической эксфолиации. Метод ХОГФ более перспективен для создания кристаллитов большого размера, но не позволяет в настоящее время получить кристаллиты с идеальными структурными параметрами.

Работа выполнена при финансовой поддержке Министерства образования и науки РФ (государственное задание № 3.7335.2017/9.10).

\section{Список литературы}

[1] Tsai M.-L., Su S.-H., Chang J.-K., Tsai D.-S., Chen C.-H., Wu C.-I., Li L.-J., Chen L.-J., He J.-H. // ACS Nano. 2014. V. 8. N 8. P. 8317-8322.

[2] Late D.J., Doneux T., Bougouma M. // Appl. Phys. Lett. 2014. V. 105. N 23. P. 233103.

[3] Zhang W., Huang J.K., Chen C.H., Chang Y.H., Cheng Y.J., Li L.J. // Adv. Mater. 2013. V. 25. N 25. P. 3456-3461.

[4] Karande S.D., Kaushik N., Narang D.S., Late D., Lodha S. // Appl. Phys. Lett. 2016. V. 109. N 14. P. 142101.

[5] Ubaldini A., Jacimovic J., Ubrig N., Giannini E. // Cryst. Growth Design. 2013. V. 13. N 10. P. 4453-4459.

[6] Geim A.K., Novoselov K.S. // Nature Mater. 2007. V. 6. N 3. P. 183-191.

[7] Jeon J., Jang S.K., Jeon S.M., Yoo G., Jang Y.H., Park J.-H., Lee S. // Nanoscale. 2015. V. 7. N 5. P. $1688-1695$.

[8] Лавров С.Д. // Российский технологический журнал. 2016. Т.4. № 4. С. 1120.

[9] Mak K.F., Lee C., Hone J., Shan J., Heinz T.F. // Phys. Rev. Lett. 2010. V. 105. N 13. P. 2-5.

Письма в ЖТФ, 2018, том 44, вып. 22 
[10] Мишина Е.Д., Шерстюк Н.Э., Шестакова А.П., Лавров С.Д., Семин С.В., Сигов А.С., Митиоглу А., Ангел С., Кулюк Л. // ФТП. 2015. Т. 49. № 6. C. $810-816$.

[11] Yu J., Li J., Zhang W., Chang H. // Chem. Sci. 2015. V. 6. N 12. P. 6705-6716.

[12] Plechinger G., Mann J., Preciado E., Barroso D., Nguyen A., Eroms J., Schüller C., Bartels L., Korn T. // Semicond. Sci. Technol. 2014. V. 29. N 6. P. 064008.

[13] Wu S., Huang C., Aivazian G., Ross J.S., Cobden D.H., Xu X. // ACS Nano. 2013. V. 7. N 3. P. $2768-2772$.

[14] Ly T.H., Chiu M.-H., Li M.-Y., Zhao J., Perello D.J., Cichocka M.O., Oh H.M., Chae S.H., Jeong H.Y., Yao F., Li L.-J., Lee Y.H. // ACS Nano. 2014. V. 8. N 11. P. 11401-11408. 